\title{
RELAÇÕES FAMILIARES E COTIDIANO: A ANÁLISE DE QUATRO ESTUDOS À LUZ DE MICHEL MAFFESOLI
}

\author{
FAMILY AND DAILY RELATIONSHIPS: \\ THE ANALYSIS OF FOUR STUDIES UNDER MICHEL MAFFESOLI'S THOUGH \\ RELACIONES FAMILIARES Y EL COTIDIANO: \\ ELANALISE DE CUATRO ESTUDIOS NA PERSPECTIVA DE MICHEL MAFFESOLI
}

Valéria Silvana Faganello Madureira*
Maria Angélica Pagliarini Waidman**
Edilza Ribeiro*
Maristela Stamm*

RESUMO: Este estudo teve por objetivo analisar o processo de viver no cotidiano, evidenciando as relações familiares. Para o alcance do mesmo, optamos por fazer uma análise de documentos, ou seja, de três dissertações de mestrado e uma tese de doutorado, sendo que os dados foram coletados a partir de quatro questões norteadoras vinculadas ao objetivo geral do estudo: quais os componentes do processo de viver as relações familiares no cotidiano? Quais as dificuldades que as famílias encontram na convivência cotidiana com o doente mental? Quais as formas de manejo apresentadas pelas famílias em diferentes situações no convívio cotidiano com o alcoolista? Qual a percepção do ser e viver saudável da mulher no seu cotidiano? Na análise dos dados, buscamos convergências e divergências que nos permitissem uma melhor compreensão dos aspectos em estudo. Para alcançar esta compreensão, utilizamos as categorias de análise do cotidiano - propostas por Maffesoli (1984) - jogo duplo, astúcia, silêncio, aceitação da vida e solidariedade orgânica.

PALAVRAS CHAVE: R elações familiares; Saúde da família

\section{ENTRANDO EM CENA...}

No sentido de compreender o processo de viver saudável na família, consideramos importante dar destaque a alguns conceitos que julgamos essenciais nesta empreitada. 0 palco no qual se desenrola o processo de viver da família é o cotidiano, que, de acordo com Ferreira (1986), significa aquilo que se faz ou que acontece todos os dias, que habitualmente se pratica.

Esta definição nos dá a impressão de repetição ou, utilizando um termo muito conhecido na Enfermagem, de rotina. Nascimento (s/d) ressalta outras características do cotidiano, sustentando que ele se manifesta por atos efêmeros, guiado pela "ética do instante"descrita por Maffesoli (1998) e que esta busca a compreensão de um sujeito concreto, plural, inserido em um espaço e em um tempo que é circular; valoriza sentimentos, paixões, imagens e fantasias, não se coadunando com esquemas pré-estabelecidos que enquadram e impõem um dever-ser.

É neste cotidiano que se dá a vida de todo dia, pontuada por pequenos momentos plenos de significado (Rezende, 1995). Acrescenta, ainda, que a proposta de compreensão da vida cotidiana fundamenta-se numa visão micro-social, vendo nela um locus privilegiado de manifestações de uma "força vital que independe de explicações econômico-políticas. Os pequenos fatos da vida cotidiana assumem relevância e a banalidade do dia-a-dia mostra sua importância". É nesse cotidiano que a vida acontece, e dentro dessa estão as relações familiares, um dos focos deste estudo.

* Enfermeiras, mestres em Enfermagem, doutorandas em Filosofia da Enfermagem na Universidade Federal de Santa Catarina

** Enfermeira, mestre em Enfermagem, professora da Universidade Estadual de Maringá e doutoranda em Filosofia da Enfermagem na Universidade Federal de Santa Catarina, bolsista do CNPq. 
Acreditamos, neste momento, ser necessário descrever o que consideramos neste estudo como família saudável:

"...uma unidade que se auto-estima positivamente onde os membros convivem e se percebem mutuamente como família. Tem uma estrutura e organização para definir objetivos e prover os meios para o crescimento, desenvolvimento, saúde e bem-estar de seus membros. A família saudável se une por laços de afetividade exteriorizados por amor e carinho, tem liberdade de expor sentimentos e dúvidas, compartilha crenças, valores e conhecimentos. Aceita a individualidade de seus membros, possui capacidade de conhecer e usufruir de seus direitos, enfrenta crises, conflitos e contradições, pedindo e dando apoio a seus membros e às pessoas significativas. A família saudável atua conscientemente no ambiente em que vive, interagindo dinamicamente com outras pessoas e famílias em diversos níveis de aproximação, transformando e sendo transformado. Desenvolve-se com experiências construindo sua história de vida." (Elsen, p.68,1994)

A família é constituída por pessoas e é importante dentro deste todo estarmos atentos para a individualidade e unicidade de cada um. Por esse motivo achamos importante trabalhar o conceito de ser saudável e não apenas de família saudável. Para Madureira (1994, p.21), Ser Saudável é:

Um processo expresso na arte de viver a partir da postura ativa assumida pelo ser humano frente as diversas situações geradas em suas relações no e com seu mundo, variável de acordo com sua competência inata ou adquirida para enfrentá-las e que lhe possibilita movimentar-se em busca do ser mais, re-criando de forma saudável sua arte de viver, transformando a si e a seu mundo.

0 desejo de desenvolver um trabalho desta natureza está vinculado à nossa familiaridade com os temas família e mulher na família, e ao desenvolvê-lo, temos por objetivo analisar o processo de viver no cotidiano evidenciando as relações familiares em algumas situações específicas. P ara 0 alcance deste objetivo, optamos por fazer uma análise de documentos, ou seja, de três dissertações de mestrado e uma tese de doutorado: Madureira (1994), Plass (1996), Waidman (1998) e Stamm (2000), sendo que os dados foram coletados a partir de quatro questões norteadoras vinculadas ao objetivo geral do estudo:

Quais os componentes das relações familiares no processo cotidiano de viver?

Quais as dificuldades que as famílias encontram na convivência cotidiana com o doente mental?

Quais as formas de manejo apresentadas pelas famílias em diferentes situações no convívio cotidiano com o alcoolista?

Qual a percepção do ser e viver saudável da mulher no seu cotidiano?

$\mathrm{Na}$ tentativa de compreender a multidimensionalidade do viver em família no seu cotidiano, buscamos nos estudos analisados enfocar os componentes do processo de viver que respondessem às questões acima, e na análise dos dados, buscamos convergências e divergências que nos permitissem uma melhor compreensão dos aspectos em estudo. Para alcançar esta compreensão, utilizamos as categorias de análise do cotidiano propostas por Maffesoli (1984) - jogo duplo, astúcia, silêncio, aceitação da vida e solidariedade orgânica, as quais serão melhor discutidas na terceira parte deste trabalho.

\section{ATUANDO...}

Tomando como ponto de partida as questões norteadoras propostas, apresentamos uma breve análise dos estudos realizados neste trabalho, no sentido de compreender o cotidiano em família e a inserção da mulher neste contexto.

\section{AS RELAÇÕES FAMILIARES E O COTIDIANO}

Abordar a multidimensionalidade do processo de viver da família requer o exame do cotidiano das relações familiares. Os fenômenos do ciclo vital, o viver de experiências inusitadas, o ser saudável, adoecer, 0 inserir-se em grupos e no contexto comunitário, as possibilidades do viver criativo dos sujeitos e do grupo 
familiar, sua qualidade de vida, se configuram e ganham expressão nas e pelas relações familiares que se fazem presentes no cotidiano.

Nascimento (s.d.) aponta finalidades ao destaque do cotidiano: o relevo e a compreensão de minúsculas situações do dia-a-dia sem suas repetições e movimentos, vividas por sujeitos concretos e plurais. 0 cotidiano se manifesta por meio de atos efêmeros que se esgotam em si mesmos (ética do instante), valoriza os pequenos acontecimentos por meio dos quais a vitalidade do grupo se manifesta e mantém. 0 cotidiano encontra-se ainda nos sentimentos, nas paixões, nas imagens e na fantasia, e se pode constatar nas transgressões, astúcias, jogos duplos, enfim nas pequenas e eficazes resistências que se instalam e minam diversos tipos de normalização.

Embora as relações familiares se desenvolvam no contexto de interdependência e secularidade, é possível destacar alguns componentes estruturais e funcionais. Numa conformação estrutural tradicional são usualmente encontradas uma díade conjugal, uma parental, as conformações fraternais e outras provenientes de agregados, formando o que Nitschke (1999) descobre como a família do coração. Nestas reconfigurações podemos encontrar díades e tríades (mãe-filho, esposo-mãe, filho-pai-avó) ou conformações provenientes de alteração de papéis (o pai funciona como filho e nivela seu funcionamento ao dos outros filhos da unidade familiar; a avó funciona como mãe e todos os demais componentes assumem papéis de filhos, etc.).

Esta estrutura vai estabelecer um funcionamento interacional no qual podem se identificar inúmeros componentes, como as relações de poder, as condições de integração conjugal, a expressão de afeto, de intimidade, a comunicação, a negociação, o conflito e adaptação, entre outros.

Para Feréz-Carneiro (1996), a interação facilitadora da saúde mental da família possui as seguintes características: a comunicação entre os seus membros é congruente, clara, com direcionalidade e carga emocional adequadas: as regras são explícitas, flexíveis e democráticas; a liderança está presente, sendo diferenciada e democrática; os conflitos podem ser expressos, sem desvalorização e com busca de solução; a agressividade pode ser manifestada de forma construtiva e a afeição física está presente, sendo aceita pelos membros da família e possuindo carga emocional adequada; a interação conjugal é, ao mesmo tempo, diferenciada e individualizada, sendo capaz de gratificar a ambos os cônjuges; individualização se faz presente, através da preservação das identidades de cada um, ao mesmo tempo em que a identidade grupal promove a integração da família, permitindo assim a formação e explicitação de sentimentos de alta auto- estima em seus membros. Poderíamos ainda exemplificar aspectos a serem verificados na avaliação do funcionamento da família como na situação de comunicação.

A teorização do cotidiano pode novamente ser resgatada e aplicada à família nos seus incontáveis arranjos organizacionais/interacionais. Ela é um espaço privilegiado do aqui e agora, embora se constate que ela não é perfeita, que pode ser vista como um nó e não como um ninho (Perrot apud Nitscke, 1999), mas que não é possível suprimi-la. Os mecanismos de resistência passiva podem ser aplicados para contrabalançar as imperfeições do viver da família. 0 que são senão jogos duplos, teatralidade, astúcia, resistência, enfim aquilo que se constata no cotidiano dos comportamentos como por exemplo à desatenção do adolescente, 0 adiamento das tarefas, a desculpa da dor de cabeça ou excesso de trabalho para fugir à intimidade, o uso do álcool.

Com o propósito de destacar a importância da instrumentalização profissional à cerca de relacionamento familiar construída no cotidiano, e suas implicações em questões de saúde nas quais participamos do cuidado, utilizamos questões abordadas na tese de doutorado de Angela Plass, defendida na Unicamp em 1996. Para Plass (1996, p.11), "cada família tem uma realidade única, porém as famílias guardam entre si aspectos comuns".

Destacamos uma das famílias abordadas pela autora para estabelecer a relação teoria-prática, como nos propomos fazer. Tal família é composta por quatro membros: pai, com 48 anos, mãe, com 47 anos, R. com 21 anos, usuária de cocaína, de álcool e maconha, esta última desde os 16 anos, e o irmão, com 18 anos. A família tem características matriarcais, sendo a avó de $\mathrm{R}$ uma mulher forte e $\mathrm{o}$ avô uma pessoa doente e frágil. 0 pai de $R$. viveu a experiência de ser dominado pelas irmãs e, na família atual, percebe que sua sogra, esposa e filha compõem um "triunvirato" que gostaria de extinguir, mas não consegue. A filha impõe à família suas condições, desafia a autoridade dos pais e controla a família, fazendo tudo o que quer.

Os pais de R. desejavam um menino quando ela nasceu, e a autora relata também a ocorrência de uma situação problemática no início da relação mãe-bebê: R. chorava muito e a mãe não conseguia amamentá-la por problemas de rachadura no seio, o que a fazia sentir-se culpada e aflita. Isto caracterizou o que a autora chamou 
de sentimento de impotência da mãe em lidar com o bebê e com suas dificuldades individuais frente à situação. R. apresentou desnutrição quando lactente, embora a situação sócio-econômica do casal correspondesse à de classe média e ela não apresentasse nenhuma condição clínica que explicasse a desnutrição.

A sexualidade do casal só foi positiva nos cinco primeiros anos de relacionamento e há bastante tempo é permeada pela insatisfação e pelo distanciamento.

Ocorreram muitas diferenças na educação por parte dos pais com relação aos seus dois filhos. A mãe oscilava entre superproteção, rejeição e acolhimento; o pai valorizava o filho, colocando-se sempre ao lado dele. $O$ irmão de R. e seu pai são juízes severos do seu "mau comportamento". $O$ afetivo é negado e aparece em R. a tendência anti-social e a subversão.

Há falta de limites no ambiente familiar e ambigüidade de papéis vividos. $R$. teve uma filha de um relacionamento tumultuado com um homem também usuário de drogas injetáveis e seus pais criam a neta com a mãe de R., assumindo o papel de mãe da neta. Num dos depoimentos do pai de R. é possível perceber várias das questões mencionadas

“...esta foi a primeira vez que vi minha mulher ser dura com a filha. A vida inteira, desde bebê, ela a protegeu; eu achava que tinha que ser mais duro mas ela também não agia. Deixava que a mãe resolvesse. 0 problema é que sempre achei que era uma "santíssima trindade", a minha sogra, a minha mulher e a minha filha. Em educação, a última palavra sempre foi a da minha mulher. Ela decidia e eu não me envolvia."

Trabalhando com outros exemplos, P lass ressalta que a maioria dos pais se afastaram ou foram afastados de funções paternas importantes: a colocação dos limites e a proximidade com os filhos. Na situação de entrevista, mostravam-se às vezes impositivos, outras vezes, distanciados dos filhos. Acerca desta condição, o pai de R. menciona:

"lembro de uma ocasião que busquei R. numa festa. Ela deveria ter 13 anos. Ao chegar no local vi ela se agarrando com um menino. Quando cheguei em casa, briguei com ela porque este não é o padrão ético que temos em casa. A mãe dela foi contra mim, achava que não havia acontecido nada do que eu estava dizendo. A R. disse que não era verdade. Eu contestei por que vira com meus próprios olhos. Não mudou nada e, aos poucos, fui me afastando deste papel."

Plass (1996) coloca que quando há dificuldades no meio familiar e os papéis de pai, mãe e filho são negados, ocorrem confusão e caos, o que implica em limites e separação. A exclusão ou auto-exclusão do pai tanto do âmbito do casal como o familiar, deixa em aberto os papéis que Ihe correspondem, transmitindo no contexto familiar uma sensação de ambigüidade que provoca ruptura e aparentemente dá poder à mulher na família, que, em geral, compensa esta falta com a aglutinação dos filhos.

Dentro de uma família se estabelece uma série de relações em que um influencia o comportamento do outro, contribuindo para o sucesso ou fracasso na solução dos conflitos. 0 conflito internalizado é um processo interior do indivíduo, mas que pode ser externalizado, assumindo a forma de conflitos interpessoais entre familiares. A atmosfera familiar pode ser hostil, faltando coesão e cooperação.

No nível de funcionamento dinâmico da família com adolescentes que apresentam uso abusivo de substâncias, Muisener apud Plass (1996) observa que a expressão emocional nestas famílias é muito restrita, ou a família é consumida pela raiva e, nas interações entre seus membros, predomina a hostilidade e 0 medo, ou estes sentimentos são reprimidos e evitados a todo custo. Em ambos os casos, há falta de intimidade genuína. Esta situação leva a uma falha na comunicação entre os membros, os quais se tornam cada vez mais fechados.

\section{A CONSTRUÇÃO DO VIVER COTIDIANO EM FAMÍLIA}

Procurando elucidar o processo de viver e ser saudável na família, analisamos a dissertação de mestrado de Stamm (2000), intitulada "A enfermeira cuidando de famílias em situação de alcoolismo com uma abordagem transpessoal", buscando na forma como estas famílias constroem seu viver cotidiano elementos que nos possibilitem uma melhor compreensão. 
Os personagens deste estudo foram duas famílias denominadas O utono e Primavera. A Família Outono era composta por 07 membros, pai, 51 anos, alcoolista, mãe, com 49 anos, e cinco filhos, três do sexo feminino e dois do sexo masculino. Desses, três eram casados e somente a filha caçula, de 18 anos, morava com eles. A Família Primavera era composta por 4 pessoas; pai, 29 anos, alcoolista; mãe, 24 anos; uma menina de 04 anos e um menino de 03 anos. Ambas as famílias tinham a mesma necessidade: superar o alcoolismo. Contudo, cada uma reagia de maneira peculiar, deixando evidentes as diferenças.

0 alcoolista da Família Outono fazia seu quarto tratamento; no primeiro conseguira permanecer sóbrio por três meses, no segundo por dois anos e no terceiro, por doze anos. Já o alcoolista da Família Primavera iniciava seu primeiro tratamento.

A mulher da família O utono, filha de alcoolista, aprendera desde cedo com a mãe a conviver com a situação de alcoolismo, trazendo consigo recordações tristes vividas na infância e adolescência, nas quais a marca do desamor imperava na família. Seu pai era austero, rude e agressivo tanto na embriaguez quanto na sobriedade. Admirava a mãe, que nunca se lamentava, aceitando a situação como "coisa do destino". Era uma família cujos membros se percebiam como tal, mas com muitas dificuldades, viviam mais o imprevisível que o visível.

Destas dificuldades, tirou o aprendizado que punha em prática no cotidiano. Havia idealizado para si um casamento baseado no amor, respeito e principalmente sem alcoolismo. A pós alguns meses de casada, percebeu que seu marido também era alcoolista. Reproduzia, então, comportamentos aprendidos desde a infância com a mãe. Manejava as dificuldades, procurando não contrariar o marido quando ele se encontrava alcoolizado. Para tanto, encaminhava as crianças cedo para a cama a fim de evitar discussões e para que elas não presenciassem as cenas indesejáveis que geralmente ocorriam. Deixava a mesa arrumada para o jantar e 0 chimarrão pronto. A ordem era calar. Calava-se e obedecia para, na sobriedade dele, mandar. Isto a distinguia da mãe, porque esta não tivera voz ativa já que seu marido sempre fora rude mesmo em sobriedade. A situação atual era diferente, pois quando sóbrio o marido tornava-se dócil, tímido e calado. Ela, então, usava da astúcia de que fala Maffesoli (1984).

Pela astúcia, permanecendo ora na luz, ora nas sombras, esta mulher procurava manter o equilíbrio da família, buscando constantemente a superação de um viver não saudável diante da multidimensionalidade da vida. Dizia, orgulhosamente que, embora tivesse vivido inúmeras dificuldades, considerava-se saudável e feliz. Descrevia uma "força interior inexplicável", que Ihe permitia trabalhar, cuidar dos negócios da família, educar os filhos, manter os relacionamentos sociais. Para isso, valorizava os momentos de sobriedade, os quais ocorriam nos finais de semana, ocasião em que passeavam e visitavam amigos, e nas férias, sempre planejadas, viajava com toda a família. Além do citado, seu maior prazer concentrava-se no trabalho da diarista e, quando saía de suas quatro paredes para as atividades, sentia-se "aliviada e renovada", e também no trabalho que recuperava forças para enfrentar as agruras do cotidiano. Na linguagem de Maffesoli, este era seu principal respiradouro.

Durante o processo de recuperação, esta mulher mostrou-se confiante e foi o principal ponto de apoio para seu companheiro. Durante os encontros, falavam de dificuldades já passadas, retomando situações vividas não elaboradas que haviam deixado mágoas e ressentimentos. 0 casal lidava com estas situações de forma serena, como alguém que "limpa suas gavetas" para deixá-las em ordem.

Patrício (1996) diz que em algum momento somos cientistas, místicos, filósofos e artistas. Estes elementos evidenciavam-se principalmente na mulher, que ponderava, falava de um Deus forte e poderoso que não os abandonava, usava de sensibilidade para resgatar o viver saudável, a família feliz com a qual sempre sonhara, não desanimava e acreditava sempre nesta possibilidade.

A Família Primavera demonstrou ser, pelo menos no início, o oposto da família Outono. A mulher, sempre queixosa, amargurada, triste, com queixas constantes de dores físicas, filha de pai alcoolista, também sonhara com um casamento feliz. Criticava o comportamento da mãe frente ao alcoolismo do pai, achando-a submissa. Nesta situação, cresceu sem amor ou afeto em um ambiente no qual imperava a violência.

Quando seu marido chegava em casa, embriagado, na maioria das vezes não permitia que ele entrasse e, aos gritos, jogava objetos no chão. Não acreditava na possibilidade de recuperação do companheiro e não 0 incentivava neste sentido. A conversa normalmente girava em torno de fatos negativos, ela falando em tom agressivo e desafiador. Depois dos filhos, o trabalho era seu maior bem. Dizia ter prazer no que fazia, falava com orgulho de sua profissão, ressaltando ser ela a principal responsável pelo sustento da casa, já que seu 
marido nunca conseguira fixar-se num emprego, o que o levou a assumir os afazeres domésticos. Esta condição Ihe dava poder, e em muitas situações era evidente a dominação que exercia dentro do lar.

0 homem mostrava-se dependente, queixoso, considerava-se discriminado pela sociedade em função de um defeito físico na mão; sentia-se incapaz de viver longe dos pais, embora verbalizasse ser este um de seus maiores sonhos. Quando criança, fora companheiro do pai nos bares e, na adolescência, usuário de maconha. $O$ fato de depender financeiramente da mulher Ihe desagradava e, ao mesmo tempo, ele procurava, através do trabalho doméstico, mostrar sua importância e sua contribuição. Havia uma diferença visível entre as duas famílias na forma como resolviam seus problemas, na maneira como usavam suas reservas saudáveis no cotidiano. Mágoas, ressentimentos, eram observados, como também gestos de carinho.

A pós quarenta dias de acompanhamento, a transformação começa na Família Primavera. 0 lado saudável começa a emergir e eles se movimentam na busca daqueles objetivos que até então consideravam impossíveis. Com a ajuda do profissional, começam o que Krestan e Bepko apud Stamm (2000) denominam de ajuste à sobriedade. Estes autores alertam para o risco de separação de casais no início do tratamento, podendo levar de seis meses a dois anos até que todos os ressentimentos se resolvam. Nesta família a presença do profissional os levava a refletir, a ponderar, a buscar novas alternativas, e isso acontecia durante os encontros. Pouco a pouco os conflitos se desvelavam e uma nova forma de enfrentá-los acontecia. 0 profissional naquele momento servia para mediar as resistências existentes.

Analisando o descrito, percebemos que as famílias souberam, mesmo que de maneiras diferentes, aceitar a individualidade de seus membros, lidando com crises, conflitos e contradições, transformando uma realidade difícil em uma mais prazerosa, o que vem ao encontro do defendido por Elsen (1994) no conceito de família saudável.

Sobressai aqui também o papel central desempenhado pela mulher tanto na manutenção de um estado de coisas como na superação de uma situação para transformação do viver cotidiano. Se retrocedermos ainda mais no tempo vivido por estas famílias, especialmente por suas mulheres, veremos que, em suas famílias de origem, a mulher-mãe também foi central. As mulheres das famílias O utono e Primavera viviam no seu tempoespaço presente, situações já vividas por suas mães, reproduzindo ou negando completamente aquilo que suas mães faziam.

\section{DIFICULDADES DA FAMÍLIA NA CONVIVÊNCIA COTIDIANA COM UM DE SEUS MEMBROS COM DOENÇA MENTAL}

Q uando nos propusemos a analisar o processo de viver no cotidiano evidenciando as relações familiares em estudos de pós-graduação, pensávamos em discutir a forma de viver das famílias já estudadas - por outros autores, enfocando o processo de viver e ser saudável no cotidiano e as relações familiares.

Neste contexto, percebemos que as famílias encontram dificuldades na sua convivência cotidiana, e isto se torna ainda muito mais evidente quando elas possuem em seu meio um portador de doença mental.

Waidman (1998), observa que a doença mental sempre foi vista pela comunidade em geral e pelos profissionais de saúde com preconceito e estigma, e isto também pode ser observado na própria família e no doente mental. Então, o fato de ter um portador de doença mental no meio familiar torna-se um fardo para família. Muitas vezes, para o alívio das tensões e dificuldades, as famílias internam seus entes familiares durante muito tempo em instituições psiquiátricas, isolando-os do convívio familiar. Quando eles deixam a instituição psiquiátrica e voltam para casa, encontram dificuldades de adaptação e de convivência cotidiana com os demais membros da família.

P reocupada com a reinserção social do doente mental na família e na sociedade, Waidman (1998), trabalhou com duas famílias de doentes mentais, com o objetivo de compartilhar os problemas decorrentes da reinserção social, vivenciados pelos familiares de doentes mentais e ajudá-los a encontrar os subsídios necessários para o doente mental viver em comunidade. As famílias deste estudo foram chamadas de família Amor e família Afeto.

A família Amor era formada pelo pai Amor, a mãe Amor, as filhas Angel e Andréia (a portadora de doença mental) e Marcos, o marido de Angel. Moravam nos fundos desta casa 3 pessoas agregadas, as quais 
eles também consideravam como família e que tinham melhor relacionamento com Andréia que os outros componentes da família. Andréia tinha vinte e oito anos e apresentara os primeiros sintomas de doença mental aos vinte e dois anos, quando estava casada e tinha um filho de três anos. Segundo a mãe e o pai Amor, o exmarido de Andréia era um homem duro e enérgico e não aceitava a doença dela, dizia que era "sem-vergonhice".

Após vários episódios agudos da doença mental, os pais resolveram trazer a filha para dentro de sua casa para cuidar dela, pois achavam que ela estava completamente abandonada na casa, junto do marido. Desta forma, Andréia mora em casa com os pais e a irmã há três anos. Quando a trouxeram para casa e levaram-na ao hospital psiquiátrico, o ex-marido entrou com pedido de separação e de guarda do filho, o que Ihe foi concedido pelo juiz. A partir desta data, Andréia ficou morando com os pais e o relacionamento familiar era muito conturbado. As principais dificuldades que a família vivenciava eram: 1. desconhecimento dos sintomas da doença mental, o que levava à não-compreensão de certas atitudes de Andréia; 2 . desconhecimento da importância do uso contínuo da medicação psiquiátrica como reguladora dos sintomas psiquiátricos; 3 . falta de paciência entre os familiares, principalmente com Andréia; 4. os familiares eram manipulados por Andréia, principalmente quando ela queria conseguir seus desejos; 5 . a inatividade de Andréia, inclusive diante das pequenas tarefas no domicílio; 6 . dificuldade de Andréia em aceitar a doença mental e a necessidade de uso contínuo de medicamentos; 7. comportamento inadequado (estragar, jogar fora, uso excessivo) de Andréia, principalmente no que se refere ao uso de produtos de limpeza e higiene; 8 . isolamento de Andréia dos problemas da família.

A família Afeto era composta porAnja (a doente mental), que com quarenta e seis anos, há dez anos separada do marido, fora abandonada após o aparecimento da doença mental, e por três filhos adolescentes, uma filha de dezessete anos, grávida na fase final de gestação, um filho de dezesseis anos e um filho de doze anos.

Anja apresentava-se aposentada por invalidez pela doença mental. Sua tutora era sua irmã Alma, também separada do marido, a qual trabalhava fora, contava com uma renda familiar de mais ou menos dois saláriosmínimos e atualmente estava com um filho casado morando com ela em virtude de uma lesão de coluna conseqüente de um acidente. Além do filho, também estava morando com ela naquele momento a irmã Afago, de trinta e dois anos, solteira, também portadora de doença mental e que só estava ali porque o pai delas estava internado no hospital em fase terminal de câncer. Anja morava numa casa em precárias condições, praticamente um casebre, na frente da casa de Alma, que tinha melhores condições de moradia.

A família apresentava várias dificuldades no seu cotidiano: 1 . dificuldade financeira séria; 2 . dificuldade de Alma em perceber que Anja poderia ser independente em algumas atividades, principalmente para fazer compras, sair sozinha, ter seus próprios documentos, assumir alguns afazeres domésticos; 3 . limitação de Anja para exercer algumas atividades no domicílio, ou fora dele, como por exemplo, participar de reuniões na escola do filho, ir ao centro da cidade sozinha, freqüentar aulas de artesanato; 4. desconhecimento dos sintomas da doença mental; 5 . desconhecimento de formas de tornar o doente mental independente; 6 . dificuldade de relacionamento entre Anja e a nora de Alma; 7. gravidez e nascimento do bebê da filha de Anja sem que soubessem quem era o pai; 9 . dificuldade de Afago em perceber a necessidade de tomar a medicação corretamente; 10 . doença com eminência de morte do pai de Anja, Alma e Afago, sendo que o primeiro morreu no dia em que foi marcado como último na interação.

A pesar das duas famílias apresentarem doentes mentais e muitas das dificuldades encontradas no diaa-dia serem muito parecidas, a forma de cada uma lidar com a situação era completamente diferente, mostrando a singularidade do viver em família.

O problema comum encontrado nas duas famílias foi o de relacionamento, porém a forma de cada uma conduzi-lo foi diferente. Na família Amor, rapidamente a família se prontificou a observar melhor o comportamento de todos e discuti-lo nas reuniões propostas pela pesquisadora, e isto levou ao crescimento individual de cada um e a percepção do jogo de manipulação que Andréia fazia para que suas vontades fossem satisfeitas.

Já na família Afeto, Alma superprotege Anja, pensando que isto lhe faz bem, porém não percebe que esta atitude prejudica sua irmã, incapacitando-a para viver com dignidade como tem direito enquanto cidadã. 0 pensamento de incapacidade da irmã é tão natural para Alma que ela jamais pensara na importância de Anja possuir carteira de identidade, pois sempre que ela precisava, de um documento usava o de Alma, sua tutora legal, por conta da aposentadoria por invalidez. Sem perceber, Alma sempre se colocava à frente para fazer as 
coisas e tomar decisões porAnja, inconscientemente agia de forma a prejudicar a irmã, porém achava que esta atitude era positiva, pois a ajudava diminuindo suas preocupações e dificuldades.

Esta atitude de superproteção de Alma para com Anja só deixou de existir porque Alma teve um problema de ovário e útero e precisou de cirurgia e Anja pode desempenhar atividades que jamais a irmã Ihe tinha permitido executar. Quando Alma retornou do hospital e percebeu que Anja conseguiu fazer atividades e tomar decisões de que ela a julgava incapaz, o relacionamento de superproteção entre as duas começou a desaparecer, fazendo com que Anja se sentisse valorizada e capaz, ao mesmo tempo em que Alma pôde perceber a capacidade produtiva da irmã.

Um ponto interessante a ser ressaltado também na forma de viver das duas famílias é com relativo ao otimismo. A família Amor sempre se colocava otimista em tentar mudar a realidade vivenciada, como por exemplo, se pode ver:

"é mesmo... acho que você tem razão... ela faz isso mesmo (manipula), porque o amor sempre acaba fazendo o que ela quer..."

“...é, Andréia, você não é boba mesmo, tenta enganar a gente de todo jeito...mas não pensa que eu não sei que você faz isso para se aproveitar..."

A atitude da família em mudar o comportamento com Andréia partiu dela mesma, depois de orientada pela pesquisadora, mostrando-se interessada em melhorar as condições de viver em família.

Porém a família Afeto parecia pessimista para as mudanças:

"ë muito difícil comprar remédio! Será que você consegue pra mim? ... O dinheiro é pouco, é só o da aposentadoria e do salário dela (de Alma)..." (Anja).

Quando a pesquisadora propõe novas alternativas de renda, como aprender fazer crochê, tricô, bordados e outros artesanatos, a família diz:

“...Ah! Eu não tenho jeito pra isso não, quando eu tava internada no hospital eu até que tentei, mas não fazia nada, nem aqueles biquinho de guardanapo eu consegui..." (Anja).

“Ah, menina não consigo fazer nada disso! Até tenho vontade, mas não consigo não... Mas a Anja, coitada, ela até tentou... A nossa sorte é a vizinhança, que ajuda bastante, né? (Alma).

"Logo o menino tem treze anos e a gente acha um serviço pra ele no mercado e daí já ajuda, né?"

A forma como elas falavam parecia denotar desesperança, até mesmo pela forma de tratar a irmã de coitada. 0 fato de sobreviver de doações também era algo que não parecia incomodar a família, pelo contrário, diziam que todos os vizinhos eram muitos bons, que todos gostavam de Anja.

\section{A MULHER NA FAMÍLIA E O SER SAUDÁVEL NO COTIDIANO}

As mulheres sempre desempenharam um papel central na vida das famílias, com forte ênfase aos seus papéis de esposa e mãe, de tal forma que ainda hoje não é amplamente aceita a idéia de que elas possam ter uma vida à parte. No desempenho destes papéis, destaca-se a mulher cuidadora dos outros membros da família - homens, crianças, idosos - atendendo às suas necessidades dos mesmos. Esta circunstância as leva a passar de filhas a esposas e mães, cujo status é definido pelo homem no relacionamento e cujo papel é resultado de sua posição no ciclo de vida familiar (McGoldrick, 1995).

Entretanto, a entrada da mulher no mundo do trabalho e nas universidades tem provocado reflexos na família, mas mudar é difícil para as mulheres e, mesmo quando se rebelam contra as responsabilidades a elas atribuídas na manutenção dos relacionamentos familiares, sentem-se culpadas ou continuam fazendo aquilo que consideram ser de sua obrigação (McGoldrick, 1995). Esta situação tem também reflexos sobre o vínculo mulhercuidado na família, tão amplamente aceito, o qual representa uma responsabilidade cada vez mais difícil, especialmente ao considerar-se o grande número de mulheres que trabalham fora do lar em tempo integral. 
P rocurando compreender a percepção de ser e viver saudável de mulheres, examinamos a dissertação de Madureira (1994), desenvolvida a partir da experiência de E ducação em Saúde com um grupo de mulheres com filhos na idade de zero a um ano na comunidade de Ratones, ilha de Santa Catarina. Neste trabalho, ser saudável revelou-se uma dimensão essencial do viver daquelas mulheres, envolvendo elementos que não se restringem ao corpo biológico, conferindo ao conceito a multidimensionalidade reconhecida no próprio processo de viver.

Como primeira dimensão deste conceito, o grupo enfatiza a "capacidade para o desempenho de atividades da vida cotidiana", o que indica o papel central ocupado pelo trabalho no cotidiano destas mulheres, às quais cabem todas as atividades ligadas à manutenção do lar e da família, aliadas a outras atividades remuneradas, paralelas àquelas do lar, que contribuem para o sustento da família.

Entretanto, para que esta capacidade possa ser considerada clara evidência de ser saudável, não pode restringir-se à mera execução de tarefas; é preciso que se faça acompanhar por "Disposição para o trabalho", responsável pelo gostar de trabalhar e pelo prazer encontrado no trabalho.

A capacidade e a disposição para o trabalho aqui apontadas, encontram justificativa no viver destas mulheres, que se dá imerso em horas ininterruptas de trabalho, nas quais elas se desincumbem do cuidado dos filhos, do lar e do marido, por elas consideradas normais, naturais na vida, ao ponto de não serem consideradas trabalho. Além disso, desempenham outras tarefas remuneradas, em seus períodos de "folga".

O prazer de trabalhar é também manifestação de uma outra dimensão, o "Estado de Espírito", traduzido pela alegria de viver, essencial ao ser saudável, de tal forma que a doença e o doente são sempre relacionados com tristeza, desânimo e preocupação.

Neste particular, "Presença ou ausência de doença/sinais e sintomas" emerge como outra dimensão do ser saudável. Estas mulheres vêem a si mesmas como doentes, quando a doença significa incapacidade para o trabalho. Mesmo situações mais graves que solicitam tratamento específico, como hipertensão e anemia, parecem não contribuir para a percepção de si como menos saudáveis, a menos que se façam acompanhar por sintomatologia capaz de alterar o ritmo cotidiano da vida, interferindo na capacidade para o trabalho.

"O médico diz que tenho arritmia, mas eu não sinto nada, nada; eu não tenho nada, nada. Não me sinto doente, portanto o remédio tá ali, ó. Não tomo mais."

Podemos então dizer que, para este grupo de mulheres, ser saudável inclui a possível ocorrência de doenças, o que coloca saúde e doença integradas, fundidas, envolvidas no viver humano. A valorização da capacidade para o trabalho condiciona também a percepção da doença, geralmente admitida como tal quando e enquanto houver uma sintomatologia presente, o que pode levar a pessoa a protelar a busca de ajuda ou a negligenciar o tratamento.

Ser saudável não inclui apenas aspectos individuais, mas se expande para além dele, traduzindo-se nas relações com outras pessoas, no "Convívio Social". Este mundo de relações é marcado pelo afeto, pela confiança e pela solidariedade e tem por espaço um território geograficamente limitado. Neste micro-cosmo em que se dá o viver, origina-se a percepção de "Nós" que ultrapassa a vida individual. (Maffesoli, 1995).

Neste convívio social manifesta-se também a necessidade de "Segurança Afetiva", intimamente relacionada com a família, o amor e o carinho que ela representa, contribuindo para a ampliação da percepção de ser saudável para além do corpo biológico, passando a incluir aspectos imateriais da existência.

Nas múltiplas dimensões do ser saudável, a “Aparência Física” surge como mais uma face, revelando que não basta sentir-se saudável, mas que também é necessário parecer saudável aos olhos dos outros, o que é essencial para o convívio social.

As "condições materiais da existência" são também essenciais e trazem novamente o trabalho como elemento básico para o suprimento destas condições, e incluem um elemento novo, pois não é suficiente poder, querer, dever e necessitar trabalhar, é preciso TER trabalho.

Mas ser saudável, conforme a percepção do grupo, exige o emprego de forças e energias, implica uma busca empreendida com os outros no mundo, o que revela uma outra dimensão: o "Esforço Pessoal". Assim, ser saudável parece o resultado de uma luta cotidiana contra a doença e contra as condições que possam apontar para ela. Neste contexto, o não se entregar, o resistir à doença, o enfrentar condições que possam levar a ela, são formas de expressão do ser saudável e revelam a preocupação destas mulheres com os outros membros da família, especialmente os filhos que dependem delas. Isto pode levar ao retardamento na busca de 
ajuda até o momento em que a gravidade da doença vença.

Há ainda um outro elemento que merece destaque e que demonstra a importância do outro, das relações interpessoais, no viver destas mulheres e que desempenha um papel importante na busca por ser saudável, que é aquilo que denominamos "rede feminina de colaboração mútua" informalmente constituída e sempre presente para ajudar as mulheres a lidar com as mais variadas situações do viver, especialmente aquelas ligadas ao cuidado da família e dos filhos. Os sujeitos desta rede são mães, irmãs, sogras, vizinhas e amigas que entram em ação em situações novas, de alegria ou sofrimento, mobilizando a si e aos outros, organizandose para ajudar. Os fios desta rede são tecidos com solidariedade e afeto.

É nesta vida comum de todos os dias que se desenrola no tempo presente que emergem as mais diversas situações com as quais as pessoas precisam lidar. No viver das mulheres do grupo, além dos afazeres domésticos, existem situações peculiares ligadas ao cuidado dos filhos e também situações ligadas ao relacionamento com o marido/companheiro, que precisam ser enfrentadas.

Ao lidar com os afazeres domésticos, as mulheres o fazem resignando-se à grande carga de trabalho que is to implica, e considerando-os como responsabilidade delas e inerentes ao viver feminino. Nas situações ligadas ao cuidado do filho, pode-se perceber que, apesar da insegurança e dos temores, as mulheres enfrentam o problema procurando resolvê-lo. Nesta forma de agir, interagem o significado que o filho assume para a mulher, o significado por elas atribuído ao papel de mãe, o significado atribuído à situação vivida e o significado da doença ou do risco de doença.

É também preciso que se considere, aqui, a relação de poder existente na relação mãe-filho. É com fundamento neste poder que a mulher toma decisões sobre o que, quando, onde, como e porque fazer alguma coisa, pois ele a investe de iniciativa, autonomia, autoridade, força e persistência. Nestas situações, a mulher busca ajuda na rede feminina de colaboração mútua, quando os recursos de sua experiência, de seu saber e de seu lar estão esgotados.

Entretanto, quando as situações vividas se inscrevem no âmbito do relacionamento conjugal, manifestase uma outra face da mesma mulher, que, ao invés de força, iniciativa, autonomia, persistência e autoridade, demonstra submissão, fragilidade, dependência, obediência e renúncia.

É importante também destacar que, para a composição desta outra face da mulher, contribui o poder existente nas relações conjugais, e que, neste caso, encontra-se principalmente nas mãos do homem, revestindoo de autoridade, imprimindo um toque de temor e respeito ao relacionamento e retirando da mulher o seu poder de decisão.

\section{ENTRECRUZANDO...}

Há, nos estudos analisados, uma série de aspectos comuns que merecem destaque, e talvez o primeiro e mais evidente seja o papel central desempenhado pela mulher nas relações familiares, o que vem ao encontro do que afirma McGoldrick (1995), sobre este assunto. No desempenho destes papéis, a mulher interpreta diversos personagens: mãe, esposa, dona-de-casa, filha, vizinha, amiga, trabalhadora (embora nem sempre se perceba como tal)...e nestes personagens, evidencia-se o compromisso/responsabilidade com o outro, a grande carga de trabalho, a participação de uma rede feminina de colaboração mútua, 0 afeto.

Pode-se perceber também o poder que permeia as relações familiares e que se evidenciou nas relações mãe-filho (Madureira, 1994), nas relações conjugais (Madureira, 1994; Plass, 1996; Stamm, 2000), nas relações dos familiares com o doente mental e deste para com seus familiares (Waidman, 1998). Aqui merece destaque o poder manifestado nas relações conjugais, o qual em geral está principalmente nas mãos do marido. Entretanto, no estudo de Plass (1996), observou-se situação inversa, manifestando-se naquela família aquilo que chamamos de supremacia do feminino.

Maffesoli (1984), fazendo uma análise do livro de Gooffman, comenta que, em diversas situações de casal, a dominação do homem sobre a mulher segue um ritual preciso que encena a rotina da vida desse casal. Nestas situações, a mulher demonstra o respeito ou submissão convencionais à vontade ou às opiniões do marido, o que revela o "conformismo" presente nas relações hierárquicas. Há, nestas situações, uma manifestação de duplicidade, que surge a partir da limitação e da imposição, criando uma arte de viver que tem no 
seu centro a distância que permite este jogo duplo.

Ao imposto, não há oposição frontal, mas uma "duplicidade dissimulada, que ao conservar as aparências de normalidade, possibilita salvaguardar a existência para si, daquilo que estrutura cada indivíduo"(Maffesoli, 1984, p.121). Os valores instituídos não são confrontados, mas contornados quando se mostram incômodos.

Pode-se perceber também a "aceitação da vida ou do destino", que inclui a duplicidade e, como ela, traduz uma atitude de resistência. Há nesta postura uma passividade fecunda, manifesta nos pequenos desvios que tentam driblar normas impostas (Rezende, 1995). Esta atitude só é possível no tempo cíclico da vida cotidiana, no qual se dá a busca por formas de enfrentar a precariedade e a permanência de um mundo ambivalente. Essa sabedoria "possibilita ser a partir da aceitação e da própria afirmação dos limites" (Maffesoli, 1984, p. 96)

A aceitação da vida foi percebida nas mulheres do estudo de Madureira (1994), que nas discussões com o marido se calavam, protegendo-se a si e aos filhos, aparentavam aceitação para, passada a crise, fazer o que decidissem, mesmo que isso lhes custasse horas de trabalho a mais e de repouso a menos. Na mulher da família O utono do estudo de Stamm (2000), também foi possível perceber esta forma de resistência quando ela protegia os filhos e recebia o marido embriagado, enfrentando calada as brigas para, na sobriedade dele, assumir o comando da família. 0 mesmo se manifestou nas mulheres das famílias Amor e Afeto do estudo de Waidman (1998) e especialmente na figura do pai no estudo de Plass (1996).

Para Maffesoli (1984), esta atitude de aceitação do limite revela-se um "deixar-ser" que, embora áspero, insere o indivíduo no ciclo orgânico da vida, no eterno retorno do mesmo, no tempo cíclico da vida cotidiana, no presente.

A duplicidade e a aceitação da vida não existem sem a máscara, que faz parte de cada indivíduo e oferece um refúgio seguro, permitindo "existir, ser - no sentido mais forte do termo - fazendo como todo mundo". A máscara, junto com a polidez, os costumes, o conformismo, o cinismo e outras tantas manifestações, são modulações de uma astúcia organicamente ligada à vida. Sobre a astúcia, diz Maffesoli (1984, p.120):

"Não se deve estranhar que a astúcia seja uma forma de resistência e que ela permita a conservação da própria pessoa. Nesta perspectiva, o homem (...) possui uma identidade de camaleão numa selva com múltiplos perigos, deve trocar de pele para sobreviver, deve ser politeísta para agradar a todos os deuses(...) em resumo, ele deve aproveitar da sombra para poder sobreviver: é nisto que reside o princípio de sua força". (Maffesoli, 1984, p.120).

A astúcia e o silêncio torna possível a resistência e a permanência da socialidade, pois astutamente as pessoas contrapõem ao instituído um silêncio polido, abrindo possibilidade para a existência em brechas do espaço social e para a manutenção da identidade e do reconhecimento (Maffesoli, 1984).

É possível perceber evidência de aceitação da vida, duplicidade, astúcia e silêncio na atitude de uma das mulheres do estudo de Madureira (1994) que, após ter aparentemente aceito o diagnóstico e a necessidade de tratamento, abandonou o uso do medicamento. Agindo assim, esta mulher decidiu sobre sua vida, resistindo, abrindo espaços entre as inúmeras normas que governam o viver evidenciado no cuidado em saúde, impondo um dever-ser. Esta é uma maneira de assegurar soberania no seu próprio viver. Cabe aqui considerar que duplicidade pode também ser deduzida no comportamento do profissional de saúde que possivelmente já adivinhava o abandono do tratamento e mesmo assim o prescreveu.

$\mathrm{Na}$ análise, pode-se perceber também a manifestação daquilo que Maffesoli (1998) denomina "solidariedade orgânica", presente em todos os estudos. Esta solidariedade privilegia o afetual, elemento mediador das relações sociais que compõem a socialidade, na qual se arraíga o mundo da vida cotidiana, feito de participação e solidariedade. Este mundo de relações, invisível mas não menos concreto, é uma manifestação desta solidariedade e coloca em evidência o valor do cotidiano no viver das pessoas como palco no qual se expressam as relações entre elas, as quais se dão na vida comum e no tempo presente da existência. A solidariedade orgânica é essencial à coesão do grupo e garante "a partilha sentimental de valores, de lugares, de idéias" (Nietschke, 1999, p. 80). Existindo esta forma de solidariedade, as formas de resistência - duplicidade, astúcia e silêncio - podem ser usadas na aceitação da vida.

Um outro ponto que merece destaque é a busca de espaços no cotidiano que permitam o que talvez 
poderíamos chamar "fuga da rotina" do dia-a-dia e do viver em família. Para as mulheres do estudo de Stamm (2000), o trabalho surgia como principal respiradouro, pois ao sair de casa, pareciam livrar-se de um grande peso, aqui representado pela situação de alcoolismo. No estudo de Madureira (1994), o grupo de E ducação em Saúde foi reconhecido pelas mulheres como um respiradouro no seu cotidiano.

Maffesoli (1984, p.66-67), fala que há, na existência, um lado iluminado, representado pela macroestrutura econômica e política, e um lado de sombra, composto por diversas situações e práticas minúsculas, lugar de conservação dos indivíduos e da espécie. Nos estudos analisados, os autores evidenciaram o lado de sombra, o vivido pelas pessoas que sentiam no seu viver os reflexos do lado iluminado, não claramente percebido.

\section{SAINDO DE CENA}

Procurando finalizar este trabalho, fazemos ainda algumas reflexões, procurando, tentando pontuar a importância e o valor da vida cotidiana para a Enfermagem e, para isso, procuramos ressaltar o papel da Enfermeira nos estudos analisados.

Entrar no mundo da família pode não ser tarefa simples, mas sem dúvida esta representa uma área expressiva para o cuidado de Enfermagem. Quando a família abre a porta do seu lar, ela está também abrindo a porta do seu mundo, de todas as pequenas e grandes situações que compõem o viver, abrindo também a possibilidade de uma melhor compreensão deste mundo, desde que se esteja aberto para perceber toda a sua dinamicidade. Neste espaço físico do lar e no âmbito das relações familiares, é possível o estabelecimento de um relacionamento mais próximo, menos formal, o que permite trocas importantes para todos.

No estudo de Stamm (2000), o referencial teórico do cuidado transpessoal de J ean Watson foi utilizado como forma de evidenciação dos elementos disfuncionais que interferiam no viver saudável da família, permitindo a busca de alternativas para os ajustamentos que se faziam necessários. Aos poucos, em um processo lento, foi emergindo uma obra de arte extraída da pedra bruta. Em cada encontro, os contornos desta obra ficavam mais nítidos, o que acontecia através do diálogo, ora com um indivíduo, ora com toda a família, ora com alguns membros da família.

Esta experiência evidencia a importância da Enfermagem no cuidar, na criação de novas situações, na efetivação de um compromisso com a comunidade, espaço onde se dá o cuidar de famílias. Enfermeira e família conseguiram construir uma unidade sólida, capaz de penetrar dúvidas, ansiedades, medos, em busca de crescimento mútuo e da superação de uma situação, o alcoolismo, sem des respeitar crenças e valores tanto da família quanto da enfermeira. 0 trabalho da enfermeira foi essencial em todo o processo de recuperação. Neste trabalho é preciso flexibilidade para perceber e atuar frente a situações imprevisíveis de um cotidiano desafiador. É importante ressaltar a necessidade da participação de outros profissionais no cuidado em famílias, de uma equipe inter, ou pelo menos, multidisciplinar.

Pensando na Enfermagem, especialmente na Educação em Saúde, podemos vislumbrar melhor a importância da compreensão da vida cotidiana, na qual se dão as relações com o outro marcadas por insignificâncias e construídas nas diferenças e cuja permanência é, segundo Bellato (1998), é assegurada por um cimento social constituído pelo desejo de ser-estar junto, do viver coletivo fundado no aqui e agora.

$\mathrm{Na}$ perspectiva de educação em saúde, o grupo se revela um espaço ideal para o diálogo, para 0 compartilhar devivências e saberes, para buscar alternativas de enfrentamento a situações vividas no cotidiano. Esta educação em saúde não é resultado de uma imposição profissional, mas fruto de uma busca coletiva construída por pessoas em grupo.

Neste grupo, do qual a enfermeira é membro, o prazer de ser-estar junto é o ponto central que dá às discussões a característica não de obrigação a ser cumprida, mas de um possível respiradouro na rotina cotidiana. Nele, a proximidade, a sensação de pertencimento, a valorização de cada um e de todos, 0 afeto, a confiança e o respeito mútuos formam o solo perfeito para a solidariedade e para a manifestação da potência, da força de cada um e do grupo, favorecendo a percepção de outras possibilidades de ser e viver saudável, de enfrentar o viver cotidiano e de transformar a si e ao mundo (visto aqui pelo lado de sombra, micro-cosmo em oposição à macro-estrutura organizacional).

Isto implica em mudança na forma de pensar e agir em Educação em Saúde, abandonando a prática 
autoritária da prescrição de cuidados "empacotados" para valorizar o outro, suas vivências e seus saberes como válidos e diferentes, dispondo-se a ouvir, a dialogar, a compartilhar para, a partir disso, poder construir, em parceria, um novo saber em saúde, mais próximo das pessoas e do seu viver.

No abandono desta prática autoritária, está implícito o reconhecimento das inúmeras nuanças da vida cotidiana, a riqueza dos detalhes, as insignificâncias, as resistências tão percebidas pela Enfermagem nos serviços de saúde e, ao mesmo tempo, tão ignoradas. Trata-se, aqui, de reconhecê-las e compreendê-las.

A ótica do cotidiano impulsiona os profissionais da saúde para uma aproximação do mundo das particularidades e minúcias, para o "des/importante", as "insignificâncias" do dia-dia da família. É possível que, por fim, se abrandem as diferenças hierárquicas, a supremacia dos saberes, e se evidenciem as identificações, abrindo espaço para a construção das parcerias desejadas. As dimensões tão tipicamente humanas da teatralidade, das resistências, das astúcias, poderão ser reconhecidas e compreendidas, uma vez que são recursos do cliente e do profissional, possibilitando, quem sabe, uma aproximação entre os Enfermeiros e aqueles com quem desenvolve o cuidar, uma maior compreensão de seres, saberes e fazeres que permita uma busca compartilhada por um viver mais saudável, respeitando os diferentes estilos do viver e ser saudável.

Não será possível pensar o tempo da família como uma reta, simples linearidade em que os acontecimentos se sucedem, como uma vida a ser vivida num futuro prometido e com pleno alcance de harmonias. 0 cotidiano desmascara os disfarces, sendo o difuso, pontual e efêmero a sua tônica.

$\mathrm{Na}$ perspectiva de análise do cotidiano busca-se o compreender, abandonando-se o julgamento, a condenação, a justificação. Isto implica um olhar atentivo dirigido ao outro para nele penetrar, buscando o significado de sua atuação, do ser - estar junto e no mundo. Valorizar a vida corriqueira, banal, de todos os dias, pode parecer algo insignificante, porém percebemos que é neste contexto que a família vive, se desenvolve, e, quando passamos a considerá-la a partir daí, podemos mais facilmente compreendê-la e descobrir formas de assisti-la nas diversas situações e dificuldades do seu viver cotidiano.

Desta forma, a Enfermagem pode reverter o risco apontado por Rezende (1997), de ocorrência da pouca reflexão e crítica na sua prática profissional, de um trabalho atado à disciplina, às normas, à rigidez, no espaço público, e à previsibilidade. A esta construção histórica o cotidiano apresenta-se como possibilidade mobilizadora e de vitalização profissional.

ABSTRACT: This study had as its objective to analyze the daily living process emphasizing the family relationships. In order to do so, we opted for doing an analysis of documents, i.e., three Master course dissertations and a doctorate thesis. We collected the data having in mind four guiding questions linked to the general objective of the study: what were the components of the process of living the family relationships in the daily routine? What are the difficulties that the families find in their daily coexistence with the mentally handicapped? How did the families handle different situations in the daily coexistence with the alcohol addicted? What was the women perception regarding being and living healthy in their daily routine? When analyzing the data, we looked for convergences and divergences that allowed us a better understanding of the aspects being studied. To reach this understanding, we used the categories of analysis of daily routines - proposed by Maffesoli (1984) - double standards, cunning, silence, and acceptance of life and organic solidarity.

\section{KEY WORDS: Family relations; Family health}

RESUMEN: Este estudio tenía como su objetivo analizar el proceso de vivir en el cotidiano, evidenciando las relaciones familiares. Por eso, optamos por hacer una analise de los documentos, es decir, tres disertaciones del maestrado y una tesis del doctorado, siendo que los datos fueram recogidos a partir de cuatro preguntas principales, ligadas al objetivo general del estudio: ¿ Cuál los componentes del proceso de vivir las relaciones familiares en el cotidiano? ¿Cuál son las dificultades de las familias con el convivio diario con el enfermo mental? ¿Cómo las familias manejaron las diversas situaciones de convivio con el alcoolista? ¿Cuál la opinión de las mujeres sobre el ser saludable y el vivir sano en su cotidiano? Al analizar los datos, buscamos las convergencias y las divergencias que nos permitieron una comprensión mejor de los aspectos que fueran estudiados. Para alcanzar esta comprensión, utilizamos las categorías de analise del cotidiano - propuesto por 
Maffesoli (1984) - juego doble, astucia, silencio, aceptación de la vida y solidariedad orgánica.

PALABRAS CLAVE: Relaciones familiares; Salud de la familia

\section{REFERÊNCIAS}

1 BELLATO, R; CARVALHO, E. C. Insignificâncias essenciais: a busca pelo reencantamento no quotidiano hospitalar. Cuiabá: EDUFMT, 1998.

2 ELSEN, I. Desafios da enfermagem no cuidado de famílias. In: ELSEN, I. et al. Marcos para a prática de enfermagem com famílias. Florianópolis: UFSC, 1994.

3 FERÉZ-CARNEIRO, T. Família: diagnóstico e terapia. 2. ed. Petrópolis: Vozes, 1996.

4 FER REIRA, A. B. H. Dicionário da língua portuguesa. 3. ed. Rio de J aneiro: Nova Fronteira, 1986.

5 MADUREIRA, V. S. F. Eu, você - nós: co-partícipes no educar. Florianópolis, 1994. Dissertação (Mestrado) - PósGraduação em Enfermagem, Universidade Federal de Santa Catarina, Florianópolis, 1994.

6 MAfFESOLI, M. A conquista do presente. Rio de J aneiro: Rocco, 1984.

7 MAFFESOLI, M. A contemplação do mundo. Porto Alegre: Artes e Ofícios, 1995.

8 MAfFESOLI, M. O tempo das tribos: o declínio do individualismo nas sociedades de massa. 2. ed. Rio de J aneiro: Forense Universitária, 1998.

9 MCGOLDRICK, M. Mulheres e o ciclo de vida familiar. In: CARTER, B.; MCGOLDRICK, M. As mudanças no ciclo de vida familiar: uma estrutura para terapia familiar. 2. ed. Porto Alegre: Artes Médicas, 1995.

10 NASCIME NTO, E. S. Compreendendo o cotidiano em saúde. Texto distribuído em sala de aula. (Mimeografado).

11 NITSCHKE, R. G. Mundo imaginal de ser família saudável. Florianópolis: UFSC, 1999.

12 PATRÍCIO, Z. M. Ser saudável na felicidade-prazer. Florianópolis: UFPel, 1996.

13 PATR ÍCIO, Z. M. PLASS, A. Algumas formas de relacionamento em famílias de adolescentes dependentes ou com uso abusivo de substâncias psicoativas. Campinas, 1996. Tese (Doutorado) - Pós-Graduação em Serviço Social, UNICAMP, 1996.

14 REZENDE, A. L. M. de. Pós-Modernidade: o vitalismo do "chaos". In: REZENDE, A. L. M.a de; RAMOS, F. R. S.; PATR İCIO, Z. M. O fio das moiras: o afrontamento do destino no quotidiano da saúde. Florianópolis: Editora da UFSC, 1995.

15 STAMM, M. A enfermeira cuidando de famílias em situação de alcoolismo com uma abordagem transpessoal. Florianópolis, 2000. Dissertação. (Mestrado) Pós-Graduação em Enfermagem, Universidade Federal de Santa Catarina, Florianópolis, 2000.

16 WAIDMAN, M. A. P. Enfermeira e família compartilhando o processo de reinserção social do doente mental. Florianópolis, 1998. Dissertação (Mestrado). Pós-graduação em Enfermagem, U niversidade Federal de Santa Catarina. 